\title{
GÉNERO Y DISCURSO CONVERSACIONAL EN EL CONTEXTO HISPÁNICO: LA EXPRESIÓN DE SOLIDARIDAD MASCULINA A TRAVÉS DEL APELATIVO MACHO ENTRE LOS OPERARIOS GALLEGOS DE UNA FÁBRICA
}

\author{
A. Virginia Acuña Ferreira \\ Universidade de Vigo \\ virginia@uvigo.es
}

\begin{abstract}
Resumen
En la línea de los estudios sobre género y discurso más recientes, que se interesan por el habla masculina prestando atención tanto a sus diferencias como a sus posibles similitudes con la interacción femenina, el presente artículo aborda el papel del apelativo macho como forma de realzar la expresión de solidaridad entre hombres (Beinhauer, 1978 [1929]), a través del análisis de varios ejemplos de su uso en las charlas de descanso mantenidas por los operarios gallegos de una fábrica. En este análisis se identifican algunas funciones más específicas de este apelativo, relacionándolas estrechamente con el tipo o subtipo de charla en el que se utiliza más concretamente (charla de cortesía, habla peyorativa sobre los gays, quejas por los superiores, producción de historias). De este modo, el artículo trata en general de contribuir a un mejor conocimiento de las características del "habla de los hombres" en el contexto hispánico, en donde los estudios sobre género y discurso conversacional tienen escaso desarrollo.
\end{abstract}

PALABRAS CLAVE: habla masculina, apelativo macho, solidaridad, funciones específicas.

\begin{abstract}
In line with most recent studies on gender and discourse, which address male talk paying attention both to differences and similarities with female interaction, the present article addresses the role of the appellative macho as a way of enhancing the expression of solidarity among men (Beinhauer, 1978 [1929]), by analyzing several examples of its use in time-out chatting among male workers of a factory. This analysis identifies some more specific functions of this appellative, relating them with the type or subtype of chatting in which this is employed more exactly (polite chatting, pejorative talk about gays, complaints about superior, telling stories). In this way, the article is generally intended to contribute to a better knowledge of the characteristics of "men's talk" in the Hispanic context, in which studies on gender and conversational discourse are not much developed.
\end{abstract}

KEY WORDS: male talk, appellative macho, solidarity, specific functions. 


\section{El habla de los hombres en los estudios sobre género y discurso}

Durante gran parte de su trayectoria, los estudios sobre género y discurso no han prestado una atención específica al habla masculina, sino que se han centrado casi exclusivamente en debatir los rasgos del habla femenina desde distintos ángulos. La publicación del trabajo de Robin Lakoff, Language and woman's place (Lakoff, 2004 [1975]) ejerció sin duda una enorme influencia a este respecto. Basándose en intuiciones acerca de su propio discurso y el de sus conocidas, Lakoff argumentó que las mujeres son educadas desde niñas para hablar con "excesiva" delicadeza, evitando el uso de tacos o la realización de afirmaciones que puedan resultar demasiado tajantes, por ejemplo. Según Lakoff, este estilo de habla se considera "femenino", pero también puede verse como "inseguro" o "carente de autoridad", por lo que su aprendizaje y utilización representa un serio inconveniente para las posibilidades de éxito profesional de las mujeres. Su descripción del habla femenina como una cuestión problemática provocó en un primer momento numerosas críticas (véase, por ejemplo, McConnell-Ginet, 2004) y llevó a muchas lingüistas a defender la necesidad de abordar el habla de las mujeres desde un punto de vista más positivo, como una variedad diferente (a la masculina), pero igualmente válida. Aunque las intuiciones de Lakoff se sitúan dentro del contexto de la sociedad estadounidense, lo cierto es que sus reflexiones sobre las reglas del "habla de una señorita" parecen aplicables a otras muchas sociedades y culturas. En el contexto hispánico también se ha resaltado, más recientemente, la tendencia al eufemismo como uno de los rasgos esenciales del "lenguaje femenino" (López García y Morant, 1991; Mouton, 2003).

Contraponiéndose al enfoque "deficitario" de Lakoff (2004 [1975]), Jones (1980) trató de promover una investigación exhaustiva de los aspectos formales del comadreo de las mujeres como un acontecimiento comunicativo que desempeña un papel clave en el refuerzo de la solidaridad femenina y que condensa los "verdaderos" rasgos de sus patrones de habla. Respondiendo a su propuesta, Coates (1988, 1996, 1997a, 1997b) ha señalado la importancia de las confidencias personales como estrategia para la creación de un alto grado de intimidad y solidaridad en la comunicación entre mujeres, a través del análisis de un corpus de conversaciones entre amigas británicas. Además, esta investigadora enfatiza la organización de estas interacciones de acuerdo con las reglas de un turno colaborativo (Edelsky, 1981), que permiten la co-construcción de los enunciados y la frecuente superposición de voces como señal de gran implicación con los temas íntimos que se tratan. El análisis de Günthner (1997) de las historias de queja como un género conversacional "femenino" constituye otro exponente de lo que Johnson (1997) ha denominado como la perspectiva de la 
"celebración" de los estilos interaccionales de las mujeres. Este tipo de historias constituyen reconstrucciones de hechos pasados en los que la narradora-protagonista se vio afectada por la conducta de una o varias terceras personas; se trata de narrativas que transmiten lo que Boxer (1993) llama quejas indirectas, en la medida en que la(s) interlocutora(s) no es tratada como responsable de lo sucedido, sino esas terceras personas que desempeñan el papel de antagonistas dentro del mundo narrado. La hablante reconstruye los hechos precisamente con el fin de obtener una respuesta afiliativa de la audiencia en contra de esos personajes. Günthner (1997) llama la atención sobre el hecho de que esta actividad se realice casi exclusivamente en las conversaciones entre mujeres alemanas de su corpus, como evidencia de la alta importancia que las mujeres conceden a la expresión de apoyo, empatía y solidaridad a través de la comunicación. Estudios recientes como el de Holmes (2006) también realzan los aspectos positivos de las habilidades verbales que están socialmente consideradas como "femeninas", tratando de invalidar los prejuicios y los estereotipos que cuestionan la capacidad profesional de las mujeres por su forma de hablar y de comunicarse (véase también Acuña Ferreira, 2009a).

A pesar de las diferencias en la perspectiva proyectada, los estudios comentados se asemejan en la medida en que ponen el foco de atención sobre el habla femenina y aluden al discurso masculino sólo de manera implícita (Johnson, 1997). Inicialmente, este desequilibrio estaría justificado, si se tiene en cuenta que el habla de los hombres había sido abordada como la norma durante varias décadas de investigaciones lingüísticas ${ }^{1}$. Hasta el auge del movimiento feminista en la segunda mitad de los años setenta, muchos estudios en los que se analizaban usos lingüísticos de hombres eran presentados como análisis de la lengua de la comunidad, como es el caso del libro Language in the inner city de Labov (1972), sobre las formas de interacción de adolescentes masculinos afroamericanos. La conocida descripción del ritual de los insultos que aquí se incluye inspiró la realización de numerosos estudios en los que se documentan otras diversas variedades de competición verbal lúdica entre hombres de distintas culturas (por ejemplo, LeMasters, 1975). Estas primeras investigaciones sobre el habla de los hombres se caracterizan por la ausencia de una perspectiva de género, como decimos, ya que las prácticas verbales documentadas no se relacionan con la masculinidad ni se comparan con las de las

1 Así, por ejemplo, García Mouton (1999) ha destacado la tradicional exclusión de la mujer como informante en las primeras investigaciones dialectales: "a pesar de sus innegables ventajas como informante dialectal -no haber salido del pueblo para hacer el servicio militar, tener menos contacto con el exterior y, en general, menos instrucción-, la mujer no ha llegado a ser objetivo principal para los dialectólogos y, por eso, no es fácil saber cómo hablaban las mujeres en los pueblos" (García Mouton, 1999: 38). 
mujeres. Sin embargo, parece claro que tales descripciones están en el trasfondo de muchos de los estudios de género sobre la interacción femenina, cuyo énfasis en la cooperación y en la búsqueda de apoyo o solidaridad como señas de identidad del estilo comunicativo de las mujeres se contrapone implícitamente a la competición y a la reafirmación del estatus personal ante los demás como rasgos definitorios de un estilo de comunicación masculino.

En su introducción a Language and masculinity, la primera colección de artículos en los que el habla de los hombres es abordada explícitamente como tal (Johnson y Meinhof, 1997), Johnson (1997) subraya que la focalización del habla femenina en los estudios sobre género y discurso presenta dos importantes problemas. Por una parte, esta autora argumenta que, aunque en las primeras fases del desarrollo de este campo era importante abordar el habla de las mujeres con profundidad para compensar su tradicional invisibilidad dentro del panorama lingüístico, el debate sobre sus aspectos positivos y negativos ha acabado contribuyendo a que se la pueda seguir viendo como una variedad que se desvía de la norma masculina. Por otra parte, el hecho de que el habla femenina haya sido caracterizada por contraposición implícita con la masculina conlleva una visión excesivamente polarizada de los estilos comunicativos que se atribuyen a las mujeres y a los hombres, es decir, una visión en la que sólo caben las diferencias o los contrastes y se pasan por alto las posibles similitudes. Éste es un problema general de las investigaciones sobre el género en el discurso (véase Bing y Bergvall, 1996; Aries, 1996; West, Lazar y Kramarae, 2000 [1997]) al que la focalización del habla femenina ha contribuido en gran medida.

Frente a la común exaltación de las diferencias entre el habla de las mujeres y de los hombres, varios artículos que se incluyen en el volumen editado por Johnson y Meinhof (1997) ponen de relieve algunas similitudes incuestionables. Por ejemplo, Johnson y Finlay (1997) argumentan que el habla de fútbol representa un tipo de discurso equivalente al comadreo de las mujeres (Jones, 1980), en la medida en que actúa como refuerzo de la solidaridad masculina. Por otra parte, el artículo de Cameron (1997) se centra en la práctica entre hombres británicos de un género conversacional que se atribuye de forma específica a las mujeres: el cotilleo ${ }^{2}$. En su análisis, esta autora resalta la defensa de los ideales de masculinidad a través de la crítica del comportamiento de hombres a los que se tilda de homosexuales y la organización de la interacción de acuerdo con un estilo cooperativo, similar al que se relaciona con las conversaciones de las mujeres.

2 Lozano-Domingo (1995) y Romaine (1999) revisan los numerosos proverbios existentes en diferentes lenguas y sociedades en los que se transmite la idea de que el cotilleo constituye una práctica exclusivamente femenina. 
No obstante, lo cierto es que otros artículos publicados en este volumen siguen transmitiendo una visión contrapuesta de los estilos comunicativos de las mujeres y de los hombres, como es el caso de Coates (1997c). Si en sus análisis previos de conversaciones entre amigas esta autora identificaba el habla de los hombres con un estilo competitivo al enfatizar el alto nivel de cooperación de las mujeres (Coates, 1988, 1996, 1997a, 1997b), su análisis de la conversación masculina en este volumen (Coates, 1997c) establece esta caracterización de manera explícita. Según esta investigadora, frente al intercambio de confidencias personales y el turno colaborativo que organiza la charla amigable entre mujeres, la charla entre hombres se centra en el tratamiento de cuestiones impersonales y prefiere organizarse según las reglas de "uno a uno" establecidas por Sacks, Schegloff y Jefferson (1974). Estas diferencias serían resultado de formas opuestas de entender la comunicación por parte de las mujeres y los hombres: mientras que en los grupos femeninos lo más importante es reforzar los lazos interpersonales, en los grupos masculinos lo prioritario es el intercambio de información y la búsqueda de estatus dentro del grupo a través de la realización de poder experto (véase también Leet-Pellegrini, 1980).

Más recientemente, Coates (2003) analiza un extenso corpus de conversaciones informales en las que participan hombres británicos de distintas edades y clases sociales, centrándose en las múltiples formas en que los participantes reproducen sus masculinidades al contar historias. En muchos de los fragmentos analizados se observan señales de un estilo interaccional altamente cooperativo, en la medida en que muestran la co-narración de experiencias compartidas o cómo varios participantes se implican en la producción de una serie de historias relacionadas. Al constatar este hecho en su análisis, esta autora señala:

The capacity of stories told in sequence to testify to the closeness of participants means that telling second stories can be a powerful way of 'doing' friendship. It is therefore not surprising that we find story sequences in conversations involving male friends: through their careful alignment to each other in their telling of second stories, co-participants at talk can display connectedness with each other, while at the same time telling stories of heroism or laddishness which construct and maintain hegemonic masculinity. (Coates, 2003: 105; énfasis nuestro)

Teniendo en cuenta sus afirmaciones previas sobre las características de la conversación entre hombres (Coates, 1997c), a nuestro modo de ver sí que resulta (o debería resultar) sorprendente el hecho de que los participantes cooperen tan estrechamente en el desarrollo de una sesión de historias y de que se centren en reforzar sus lazos interpersonales (y no sólo en reafirmar su estatus dentro del grupo). 


\section{Los estudios sobre lengua y género en el contexto hispánico}

Salvo el artículo de Günthner (1997) sobre las historias de queja entre mujeres alemanas, todos los trabajos reseñados en el apartado anterior analizan datos de hablantes anglófonos o se sitúan dentro del contexto de la sociedad británica o estadounidense. Actualmente, los estudios sobre Género y Discurso o sobre Lengua y Género representan un campo firmemente consolidado y en continua expansión dentro de los Estados Unidos y del Reino Unido ${ }^{3}$, pero su situación en otros países es bien distinta. En el caso de la lingüística hispánica, las escasas publicaciones que pueden encontrarse sobre este tema suelen ser una revisión de los estudios realizados en países anglófonos (Bengoechea, 1995; Lozano Domingo, 1995; Martín Rojo, 1996; García Mouton, 1999) y se echan especialmente en falta, por tanto, investigaciones de carácter empírico ${ }^{4}$. La reciente aparición de una serie de colecciones de artículos (Santaemilia, Gallardo y Sanmartín, 2002; Vigara Tauste y Jiménez Catalá, 2002; Acuña Ferreira y Álvarez López, 2003) indica cierto interés por promover el desarrollo de este campo, pero aún queda mucho por hacer. Es notable, por ejemplo, el esfuerzo que se ha hecho en el análisis de lo que se conoce como sexismo lingüístico, que trata de concienciar acerca de los problemas derivados del uso genérico del género gramatical masculino como una forma de discriminación de las mujeres, además de sobre otras muchas cuestiones que tienen que ver con el uso de la lengua en un nivel estructural (por ejemplo, García Messeguer, 1994; Calero Fernández, 1999). Sin embargo, el campo de los estudios sobre Lengua y Género o sobre Género y Discurso incluye en la actualidad una amplísima gama de temas sobre los que se ha trabajado poco.

El análisis del despliegue de identidades de género en la conversación constituye precisamente una de estas áreas cuyo excepcional desarrollo en el contexto anglófono contrasta con lo que sucede en nuestro entorno más cercano. En lo que respecta al habla de los hombres, tema en el que se centra el

3 Como demuestra la constante aparición de libros y colecciones de artículos en cuyo título se incluyen los términos "Gender and discourse" y nomenclaturas afines como "Language and Gender", "Gender and spoken interaction", "Gender and conversational interaction", o "Gendered talk" (por ejemplo, Tannen, 1993; Hall y Bucholtz, 1995; Crawford, 1995; Bergvall, Bing y Freed, 1996; Livia y Hall, 1997; Wodak, 1997; Coates, 1998; Bucholtz, Liang y Sutton, 1999; Baron y Kotthoff, 2002; Holmes y Meyerhoff, 2003; Holmes, 2006; Sunderland, 2006; Pichler, Pia y Eppler, 2009). En 2007 aparece Gender and Language, la primera revista especializada en la investigación sobre el género desde una perspectiva lingüística, publicada por la editorial Equinox y de la que son co-editoras Bonnie McElhinny y Sara Mills.

4 En Cómo hablan las mujeres, García Mouton (1999) reseña numerosas investigaciones que proceden de la dialectología y de la sociolingüística hispánica de tipo variacionista; los apartados en los que aborda el nivel discursivo, sin embargo, se basan en trabajos que manejan datos de hablantes anglófonos. 
presente artículo, cabe destacar las investigaciones de Pujolar (1997a, 1997b, 2002), en las que se aborda, entre otras cosas, la construcción interaccional de distintas versiones de la masculinidad entre los jóvenes de dos pandillas mixtas de Barcelona, y el análisis de Álvarez López (2002/2003) de la conversación de un grupo mixto de nueve jóvenes gallegos, en el que se resalta cómo los dos únicos chicos que participaban en la interacción interrumpían reiteradamente las historias que contaban sus compañeras haciendo observaciones burlonas, juegos de palabras y recreando escenas de populares series televisivas. Por tanto, este estudio llama la atención sobre cómo el humor puede ser utilizado por los hombres como estrategia para controlar el desarrollo de las conversaciones mixtas y de este modo ejercer poder sobre las mismas.

Nuestros trabajos anteriores (Acuña Ferreira, 2002, 2002/2003, 2004, 2008, $2009 \mathrm{~b}$ ) tratan de contribuir a incrementar el interés por las investigaciones sobre género y discurso, a través del análisis de un corpus de conversaciones "naturales" entre hablantes gallegas y gallegos del mismo sexo. En conjunto, estos análisis abordan las diversas formas en que podemos transmitir feminidad y/o masculinidad al conversar sociablemente con nuestras amistades o con nuestros/as compañeros/as de trabajo, según el tipo de actividades comunicativas que llevemos a cabo (contar historias, cotillear, compartir confidencias... etc.) y, sobre todo, según el modo en el que lo hagamos (Acuña Ferreira, 2009b). Nuestras investigaciones prestan atención tanto a las normas y estereotipos socioculturales que están ligados al "habla de las mujeres" como al "habla de los hombres", pero algunas de las publicaciones citadas (Acuña Ferreira, 2004, 2008) se centran en el análisis de fragmentos de una conversación protagonizada por tres hombres jóvenes en la que se destaca la práctica de las historias de queja, género comunicativo que, como ya se ha indicado, ha sido caracterizado como propio de la interacción femenina (Günthner, 1997). En la línea de algunos artículos incluidos en Johnson y Meinhof (1997), estos análisis demuestran la presencia de rasgos estereotípicamente femeninos en una conversación entre hombres, como el hecho de que se centre en la expresión de apoyo y solidaridad y se desarrolle de forma colaborativa, junto con aspectos fuertemente asociados a la masculinidad, como el hecho de que las historias de queja giren en tono al mundo del fútbol o de que los despliegues de indignación se basen en un estilo de habla "agresivo" (Acuña Ferreira, 2004, 2008; véase también Acuña Ferreira, 2009b).

\section{Las charlas de descanso de los operarios gallegos de una fábrica}

La mayor parte de los datos conversacionales en los que se basan nuestras investigaciones anteriores proceden del Corpus de Fala Bilingüe Galego/Castelán (Co.Fa.Bil.), proyecto formado en la Universidad de Vigo por el grupo inves- 
tigador al que pertenece la autora. Este corpus se compone de grabaciones de audio que fueron efectuadas por estudiantes de licenciatura de esta universidad, y que en la mayoría de los casos recogen las charlas que ellos mismos mantuvieron con sus amigas/os, sus familiares y sus compañeras/os de clase o de trabajo. En este artículo analizaremos una parte de los datos extraídos de este corpus, que corresponde a las interacciones mantenidas por los operarios gallegos de una fábrica de coches. Las grabaciones fueron realizadas en el transcurso de varios meses por uno de los trabajadores durante los descansos que incluye su jornada laboral, de ahí que las hayamos etiquetado conjuntamente como charlas de descanso. La Ficha 1 recoge los principales datos de contextualización de dichas grabaciones:

\begin{tabular}{|l|l|}
\hline Código & B1.97-98 \\
\hline Situación comunicativa & $\begin{array}{l}\text { Descansos durante la jornada laboral en una } \\
\text { fábrica de coches }\end{array}$ \\
\hline Participantes & $\begin{array}{l}\text { Operarios que trabajan en el turno de noche, } \\
\text { con edades comprendidas entre los veintitrés } \\
\text { y los cuarenta años }\end{array}$ \\
\hline Acontecimiento comunicativo & Sesiones de charlas de descanso \\
\hline Duración de las grabaciones & Aproximadamente dos horas y media \\
\hline
\end{tabular}

Ficha 1

El lugar de las interacciones puede describirse como un centro de trabajo estereotípicamente "masculino", semejante al analizado por Holmes y Stubbe (2003; véase también Holmes, 2006), teniendo en cuenta que la mayoría de los trabajadores son hombres que realizan tareas tradicionalmente masculinas. Desde el punto de vista del discurso, el habla que se produce durante los descansos se destaca como una poderosa forma de reforzar este "ambiente masculino" (Acuña Ferreira, 2009b), en la medida en que responde a muchos de los estereotipos que están más firmemente ligados al "habla de los hombres". En un análisis preliminar de este corpus se diferenciaron cuatro variedades o modalidades de charla de descanso: habla de contacto ${ }^{5}$, habla relacionada con

5 Así se traduce el término anglosajón small talk (Coupland, 2000) en un número monográfico de la revista Oralia sobre este tipo de discurso en español, introducido por Placencia y García (2008). La delimitación de este concepto no está nada clara, puesto que sus definiciones varían considerablemente según los estudios, pero es posible diferenciar dos 
el trabajo y habla humorística, que sirven para el establecimiento de relaciones cordiales, y habla en privado, que sirve para reforzar la relación más estrecha de amistad que se da entre ciertos operarios. A su vez, cada una de estas cuatro variedades incluye dos o más subtipos, muchos de los cuales están impregnados de masculinidad, como es el caso, por ejemplo, del habla de fútbol que se mantiene como forma de habla de contacto, o del humor de contestación (Holmes y Stubbe, 2003) que se produce como subtipo de habla humorística.

No obstante, sería inexacto afirmar que estas interacciones se ajustan a las normas y estereotipos de habla masculina con absoluta fidelidad, puesto que también se encuentran secuencias en las que se desarrollan formas de comunicación "femeninas" como las quejas, el cotilleo y las confidencias, si bien es cierto que en su estilo de realización se resaltan rasgos que contribuyen a "masculinizar" el discurso, como también sucede en las historias de queja entre hombres que se analizan en Acuña Ferreira (2004, 2008; véase también Acuña Ferreira, 2009b).

Además, desde una perspectiva global, las charlas de descanso de los operarios de este centro de trabajo cuestionan la visión polarizada de la conversación femenina como centrada en la solidaridad, frente a la conversación masculina como orientada a la promoción personal dentro del grupo (Coates, 1997c). Y es que, como se ha indicado, todos y cada uno de los tipos y subtipos de discurso sociable que se producen tienen como función primordial la expresión de compañerismo, solidaridad y/o la reafirmación de la amistad, in-

principales aproximaciones. En la primera de ellas subyace una visión amplia del small talk o habla de contacto como un tipo de discurso que se orienta fundamentalmente hacia el mantenimiento de buenas relaciones interpersonales o la demostración de sociabilidad. Aquí los términos parecen emplearse como una especie de paraguas bajo el que se incluirían múltiples variedades de discurso sociable como los saludos, el cotilleo, la producción de historias, la conversación humorística... etc. El punto de vista de la segunda aproximación es mucho más restringido, ya que aquí los términos se consideran estrictamente en relación con el concepto de comunicación fática de Malinowski (1949 [1923]). Desde el punto de vista de la primera aproximación, todas las charlas de descanso entre los operarios de una fábrica que aquí abordamos se considerarían conjuntamente como una forma de small talk o habla de contacto en la que habría que diferenciar varios subtipos, pero nosotros nos decantamos por la concepción restringida de estos términos en un sentido más próximo al de comunicación fática, como el tipo de discurso que se orienta de forma más pura hacia la expresión de cordialidad o sociabilidad. Por ello, para nosotros los cotilleos y las confidencias, por ejemplo, no constituyen conversación de contacto, o al menos, no siempre, puesto que su práctica sirve para reafirmar las relaciones interpersonales entre los interlocutores/as, pero en un nivel más profundo o más íntimo de lo que lo hace la conversación de "puro" contacto, a la que atribuimos un carácter más superficial. Naturalmente, la realidad discursiva es siempre mucho más compleja de lo que sugieren las definiciones, ya que las orientaciones del habla pueden cambiar rápidamente y con frecuencia se hace difícil poner una sola etiqueta a las interacciones reales de los/as hablantes. 
cluso aquellos que se basan en la competición lúdica y que resultan más prototípicamente masculinos.

En el presente artículo queremos precisamente llamar la atención sobre la importancia que adquiere una partícula pragmática, el apelativo macho, en la enfatización de la solidaridad masculina como meta principal de las charlas de descanso en esta fábrica. Así, en el siguiente apartado pasamos a analizar una serie de fragmentos seleccionados de estas charlas en los que pueden apreciarse los diversos matices que puede adquirir este apelativo, y por tanto las distintas funciones específicas que puede desempeñar según el contexto discursivo. Nuestro objetivo general en la realización de este análisis es el de contribuir a un mejor conocimiento de las características que presentan las conversaciones de los hombres dentro de un contexto hispánico, y de este modo promover un mayor interés por esta línea de investigación, que hasta el momento sólo se desarrolla propiamente en países de habla inglesa.

\section{Análisis de las funciones específicas del apelativo macho en el corpus}

La función del apelativo macho como forma de reforzar la solidaridad entre hombres ha sido señalada por autores como Beinhauer (1978 [1929]: 48-9; véase también López García y Morant, 1991: 99). Tras analizar su empleo en muchas de las secuencias de habla de nuestro corpus, nosotros consideramos que ésta sería su función más general, porque lo cierto es que al mismo tiempo es posible atribuirle una serie de funciones específicas que están estrechamente ligadas al tipo o subtipo de discurso sociable en el que están implicados los participantes. Cada una de las secciones en las que se divide el presente apartado se dedicará a mostrar uno de estos usos concretos.

\subsection{Para señalar afecto y cordialidad en las charlas de cortesía}

El Fragmento 1 recoge parte de una interacción en la que Diego pregunta directamente a Miguel cómo le fueron las fiestas navideñas ${ }^{6}$, y a raíz de ello se desarrolla una pequeña charla sobre la lotería de navidad. Según Holmes (2000), las preguntas sobre las vacaciones constituyen uno de los recursos más comunes y estereotipados para iniciar small talk o habla de contacto en el trabajo. Por ello, el habla que recoge este fragmento podría etiquetarse como una muestra de habla de contacto canónica (Acuña Ferreira, 2009b), pero aquí hemos preferido la denominación charla de cortesía, teniendo en cuenta que la función básica de este tipo de discurso es precisamente la de demostrar pre-

6 Todos los nombres de los participantes, así como los de las terceras personas a las que a veces se alude son sustituidos por pseudónimos para mantener su anonimato. 
ocupación por las necesidades de imagen del interlocutor, con el fin de mantener la cordialidad y de hacer compañerismo (Holmes, 2000) ${ }^{7}$ :

\section{Fragmento 1. Charla de cortesía ${ }^{8}$}

$\begin{array}{lll}1 & \text { Diego } & \text { Y QUÉ TAL::? } \\ 2 & & \text { DE FESTAS } \rightarrow \\ 3 & & . \cdot \\ 4 & \text { Miguel } & \{[\text { p] bien }\} \uparrow= \\ 5 & \text { Diego } & =\text { BIEN? } \\ 6 & & \text { PODÍAN SER MEJORES? } \\ 7 & & \text { o:: } \\ 8 & & \text { están bien } \rightarrow \\ 9 & \text { Miguel } & \text { podían ser mejores } \uparrow= \\ \cdot & & \\ \cdot & & \\ . & & \text { si:: tocara la } \rightarrow \\ 10 & \text { Miguel } & \text { la lo- } \\ 11 & & \text {.. } \\ 12 & & \text { la lotería } \uparrow \\ 13 & & \text { hubieran sido mejores } \rightarrow \\ 14 & & \text { a mí me tocaron quince billetes } \uparrow \\ 15 & \text { Diego } & \text { ma::cho } \rightarrow \\ 16 & & \text { y a mí nada macho } \rightarrow \\ 17 & \text { Miguel } & \text {.. } \\ 18 & & \text { ya (xx) [pero aún así] } \uparrow \\ 19 & & \end{array}$

$7 \quad$ Holmes (2000) analiza las funciones que cumple el small talk o habla de contacto en el trabajo y destaca que su práctica es casi obligatoria en el primer encuentro de la jornada. En estos encuentros iniciales, que tienden a producirse fugazmente en los pasillos, suelen hacerse preguntas sobre el bienestar (¿qué tal va todo?) y alusiones al clima (qué buen día hace, ¿verdad?), así como a actividades de ocio que se hayan compartido (oye, buen concierto el del otro día). El habla de contacto también es importante al comienzo de las reuniones, para evitar silencios incómodos mientras se espera a que el grupo esté completo, así como al final de las mismas, como una forma de "volver a la tierra" después de las tareas de trabajo o para restablecer la cordialidad tras un debate muy intenso. Además, a veces puede producirse en mitad de las reuniones como un paréntesis, y en los descansos para tomar el té o a la hora de comer puede ser prefacio de un discurso sociable más extenso, según el grado de confianza entre los participantes, de su estatus, de lo ocupados que estén en ese momento o de la importancia que tenga la sociabilidad en el lugar de trabajo específico.

8 Véanse las Convenciones de Transcripción en el Apéndice que se incluye al final del artículo, que se basan en el modelo de Ávarez Cáccamo (1990). 


\begin{tabular}{|c|c|}
\hline 20 Diego & [QUINCE MIL] PELAS $\uparrow$ \\
\hline 21 & y a $\rightarrow$ \\
\hline 22 & y a mi abuela otras quince $\uparrow$ \\
\hline 23 & macho $\rightarrow$ \\
\hline 24 & la misma lotería $\rightarrow$ \\
\hline 25 & he he he \\
\hline 26 & 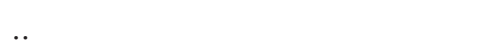 \\
\hline 27 & hosTIÁ $\uparrow$ \\
\hline 28 & COMO DIO:S $\uparrow$ \\
\hline 29 & COMPRÉN UNHAS ALETAS $\uparrow$ \\
\hline 30 & $\mathrm{MACHO} \rightarrow$ \\
\hline 31 & he he he \\
\hline 32 & e unhas ghafas $\rightarrow$ \\
\hline
\end{tabular}

Como puede observarse, la respuesta poco entusiasta de Miguel ante la pregunta de cortesía de Diego lleva a este último a insistir en su demostración de interés por el bienestar de su compañero (líneas 1-9). Instantes después, Miguel corresponde a esta expresión de cordialidad haciendo referencia a su falta de fortuna en la lotería para contribuir en el desarrollo de la charla (líneas 10-14). La introducción de este subtema característico del habla de contacto sobre las fiestas navideñas logra aumentar bastante el nivel informativo del discurso, ya que Diego comenta entonces que tanto él como su abuela recibieron cierta cantidad (líneas 15-16, 20-24) y expresa su satisfacción por ello de manera un tanto jactanciosa y muy estereotípicamente masculina, a través de la risa (línea 25) y de exclamaciones "ordinarias" de alegría, hosTIÁ $\uparrow$ (línea 27), COMO DIO:S $\uparrow$ (línea 28). A continuación, este participante resalta además las cosas que se compró con el dinero recibido, sin dejar de reírse ni de emplear este tono de euforia (líneas 29-32).

Mientras que los primeros turnos se ajustaban plenamente a las definiciones de comunicación fática en su sentido más literal (Malinowski, 1949 [1923]; Coupland, 2000), en la medida en que presentaban un nivel mínimo de información y un carácter convencional, en estos últimos turnos se pone de relieve cómo la alusión de Miguel a la lotería tiene éxito como estrategia para mantener el habla de contacto, al dotarla de cierto contenido.

Mediante su estrecha cooperación en el mantenimiento de esta charla de cortesía, los dos trabajadores demuestran que se preocupan mutuamente por las necesidades de imagen del otro y de este modo confirman su buena relación como compañeros de trabajo. El tono cordial de la interacción se ve realzado por los usos que Diego hace del apelativo macho para llamar la atención de su 
interlocutor sobre las novedades que va introduciendo en su discurso de manera afectiva (líneas 15-16, 22-23, 29-30), pero esta cordialidad se pone especialmente de relieve entre las líneas 15-17, cuando Miguel se hace eco del empleo de este vocativo por parte de su compañero precisamente en el turno anterior: (Diego) a mí me tocaron quince billetes $\uparrow$ (línea 15), ma::cho $\rightarrow$ (línea 16); (Miguel) y a mí nada macho $\rightarrow$ (línea 17).

\subsection{Para señalar complicidad en el habla peyorativa sobre los gays}

El Fragmento 2 ha sido seleccionado de una interacción que también clasificamos como conversación de contacto, ya que en ella participan varios operarios que comentan cómo pasaron el fin de semana. En determinado momento de esta interacción se alude a un bar nocturno en el que la mayoría de los clientes son hombres homosexuales. Entonces, algunos de los participantes comentan haber estado allí en alguna ocasión, sin saber que se trataba de un local de ambiente gay. En general, la charla se centra en la demostración de desprecio hacia este colectivo, de ahí que la hayamos etiquetado, más concretamente, como habla peyorativa sobre los gays:

\section{Fragmento 2. Habla peyorativa sobre los gays}

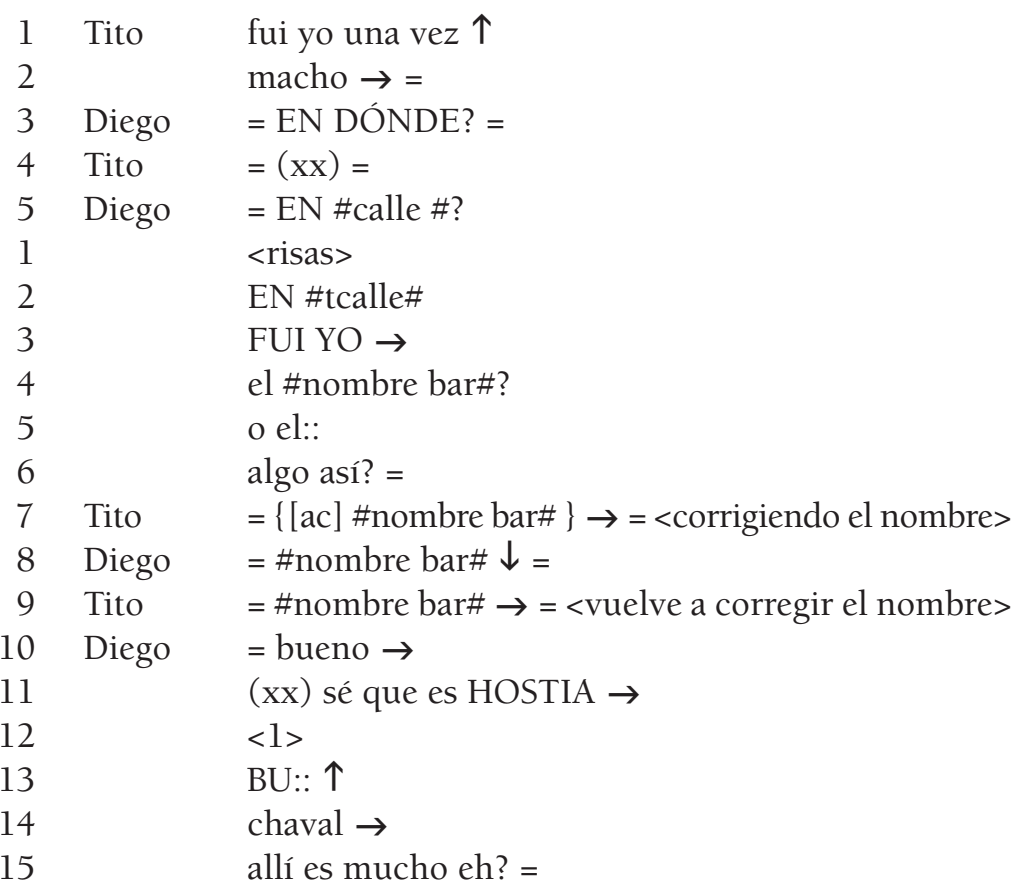




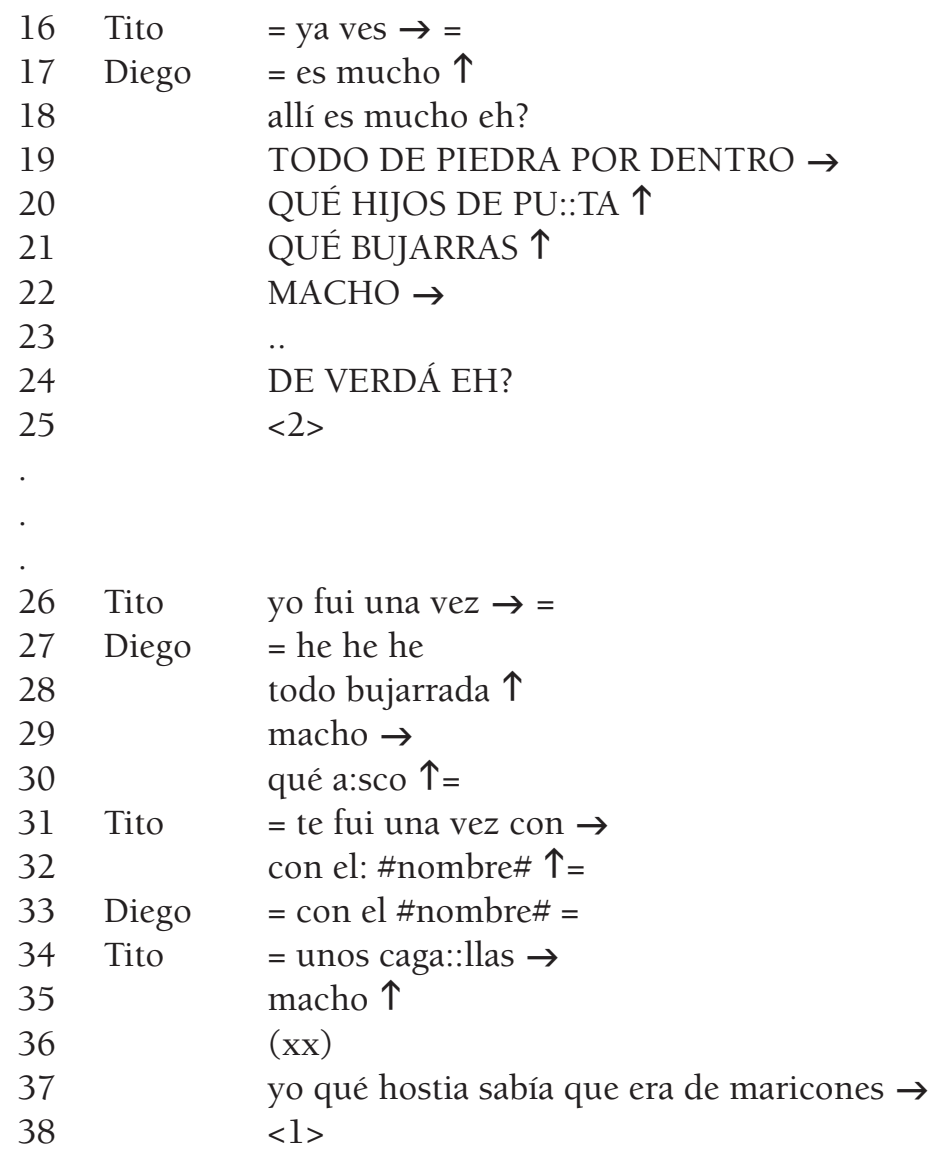

Los primeros turnos recogen una intervención de Tito reconociendo haber estado una vez en el local en cuestión (líneas 1-2) y las sucesivas de Diego intentando confirmar que se trata del mismo bar en el que él también estuvo (líneas 3-16). Una vez que esto queda aclarado, Diego enfatiza su asombro ante el número de hombres homosexuales que acuden a este bar y solicita el acuerdo de su compañero con respecto a esta circunstancia, utilizando recursos para apelar al interlocutor como los vocativos y las preguntas coletilla de forma reiterada, BU:: $\uparrow$ (línea 18), chaval $\rightarrow$ (línea 19), allí es mucho eh? (línea 20), es mucho $\uparrow$ (línea 22), allí es mucho eh? (línea 23). La respuesta de Tito, ya ves $\rightarrow$ (línea 21), sugiere su decepción ante el ambiente gay que allí se encontró.

Seguidamente, Diego prodiga insultos en voz alta contra los clientes habituales de este bar y se refiere a ellos de forma peyorativa, QUÉ HIJOS DE

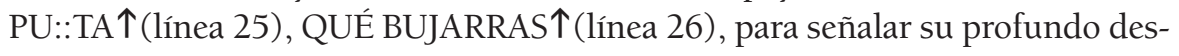


precio por los hombres homosexuales y enfatizar su heterosexualidad. Tras una pequeña pausa (línea 28), este trabajador apela nuevamente a sus compañeros para invitarles a demostrar afiliación con su postura homofóbica, DE VERDÁ EH? (línea 29), y vuelve a expresar su rechazo hacia el colectivo gay, he he he (línea 32), todo bujarrada $\uparrow(l i ́ n e a ~ 33)$, macho $\rightarrow$ (línea 34), qué a:sco $\uparrow$ (línea 35). Entonces Tito especifica el nombre de la persona que le acompañó al bar (líneas 36-37) y termina afiliándose con la postura de Diego, al describir la clientela habitual de este local de manera igualmente peyorativa, unos caga::llas $\rightarrow$ (línea 39), macho $\uparrow($ línea 40). Finalmente, este trabajador justifica su presencia en el bar en cuestión afirmando que desconocía el hecho de que fuese frecuentado por hombres homosexuales, a quienes se refiere vez más en términos peyorativos, yo qué hostia sabía que era de maricones $\rightarrow$ (línea 42).

En esta charla se pone de relieve la importancia de la homofobia en los modelos predominantes de masculinidad (Connell, 1995; Edley y Wetherell, 1997; Gough y Edwards, 1998; Coates, 2003), ya que Diego parece interpretar la alusión a un bar de ambiente gay como una invitación a demostrar su rechazo hacia este colectivo. Con su insistencia en la demostración de homofobia y su apelación reiterada a los demás participantes, este operario reclama implícitamente el cumplimiento de la norma: "men in all-male groups must unambiguously display their heterosexual orientation" (Cameron, 1997: 61). Aunque no lo consigue de inmediato, finalmente Tito descalifica de modo semejante a los clientes habituales del local en cuestión y señala así su afiliación con Diego. El uso apelativo de macho que los dos trabajadores hacen en varias ocasiones (líneas 1-2, 26-27, 33-34, 39-40) contribuye a reforzar esta complicidad heterosexual como base para la realización de solidaridad masculina, llamando implícitamente la atención sobre las connotaciones sexuales del término, que a veces se utiliza para elogiar la potencia sexual de un hombre con las mujeres, junto con su variante machote (López García y Morant, 1991: 134, 173)9.

\subsection{Para suscitar la empatía del interlocutor en la expresión de quejas}

En su aproximación al habla de contacto en el trabajo, Holmes (2000) resalta las dificultades de atribuir una sola función a las diversas formas de discurso que encuentra en su propio corpus. El habla de contacto se ha considerado tradicionalmente de forma peyorativa como un discurso "trivial" y carente de

9 En una de las conversaciones entre mujeres jóvenes que constituyen nuestro corpus, las participantes utilizaron la expresión macho cabrío para describir a un joven que presumía de mantener relaciones sexuales con muchas mujeres (Acuña Ferreira, 2009b: 174-175). 
contenido que "solo" cumple una función afectiva, por contraposición implícita con el habla "importante" que se orienta al cumplimiento de determinada tarea y que tiene una función referencial. Sin embargo, en realidad podemos encontrar muchas variedades de discurso que se situarían a medio camino entre estos dos extremos, como por ejemplo, el habla relacionada con el trabajo que en ocasiones se produce en las situaciones de ocio. De acuerdo con lo que Holmes (2000; véase también Holmes y Stubbe, 2003: 89-90) encuentra en su corpus, las charlas de descanso entre operarios de las que aquí nos ocupamos incluyen algunas muestras de cómo los temas laborales pueden "invadir el tiempo social" en los centros de trabajo. En nuestros datos, esta invasión se debe fundamentalmente a las historias de queja (Günthner, 1997) o quejas indirectas (Boxer, 1993) que se expresan en relación con el comportamiento de determinados superiores. Los casos de este tipo de discurso se han clasificado como un subtipo de habla relacionada con el trabajo que sin duda desempeña un papel esencial en el refuerzo de los vínculos de solidaridad grupal entre los trabajadores, pero que, a nuestro modo de ver, no debería considerarse como habla de contacto, en la medida en que su contenido tiene que ver con cuestiones "serias", ni tampoco como habla de trabajo propiamente dicha, puesto que no se orienta al cumplimiento de determinada tarea.

El Fragmento 3 se ha extraído de una interacción en la que Diego se queja a su compañero Roberto porque un superior le ordenó cambiarse de puesto. El trabajador despliega una gran indignación por este hecho, a través de tacos e insultos que van dirigidos a esa tercera persona, y obtiene la solidaridad de Roberto, que critica el comportamiento de este superior argumentando que no tiene autoridad para dar esa clase de órdenes. Los primeros turnos que se recogen corresponden precisamente al momento en el que este operario está desarrollando su discurso de apoyo a Diego:

Fragmento 3. Quejas por la orden de un superior

$\begin{array}{rll}1 & \text { Roberto } & \text { el bota } \rightarrow \\ 2 & \text { vai por aí: } \uparrow \\ 3 & \text { botando un } \rightarrow \\ 4 & \text { un ollo } \uparrow \\ 5 & \text { e cando tal } \uparrow \\ 6 & \text { pois: } \rightarrow \\ 7 & \text { bótalle unha man } \uparrow \\ 8 & \text { \{[ac] SE QUERE\} } \rightarrow \\ 9 & \text { se é: } \rightarrow \\ 10 & \text { se é: } \rightarrow\end{array}$




$\begin{array}{lll}11 & & <1> \\ 12 & & \text { se é un pouco PERSOA } \downarrow \\ 13 & & <3> \\ 14 & \text { Diego } & \text { es que es eso } \uparrow \\ 15 & & <5> \\ 16 & \text { Roberto } & \text { el non } \downarrow \\ 17 & & \text { el anda de iDIOta por aí } \rightarrow \\ 18 & & <2> \\ 19 & \text { Diego } & \text { él anda de papahostias } \rightarrow \\ 20 & & <2> \\ 21 & & \text { es que no lo puedo ver } \uparrow \\ 22 & & \text { macho } \rightarrow \\ 23 & & \text { me da un a:sco } \uparrow \\ 24 & & \text { tío } \uparrow \\ 25 & \text { muerto de hambre de MIE::Rda } \uparrow \\ 26 & & \text { asqueroso } \uparrow \\ 27 & <2>\end{array}$

Argumentando sobre las razones por las que el comportamiento del superior no es el adecuado, Roberto sostiene que su función principal es la de controlar las tareas que realizan los operarios (líneas 1-4) e insiste en que además debería ayudarles si fuese necesario (líneas 5-12). Diego expresa su acuerdo con este razonamiento (línea 14) y, varios segundos después (línea 15), su compañero critica al personaje en cuestión por no cumplir con estas expectativas, describiendo muy despectivamente su comportamiento a través del insulto: el non $\downarrow$ (línea 16), el anda de iDIOta por aí $\rightarrow$ (línea 17). Tras una pausa (línea 18), Diego se hace eco de la evaluación previa de Roberto para señalar nuevamente su acuerdo, él anda de papahostias $\rightarrow$ (línea 19). Poco después (línea 20), este trabajador expresa un profundo rechazo hacia el personaje y apela reiteradamente a su interlocutor a través del uso de macho y también de tío, como estrategia para suscitar su empatía: es que no lo puedo

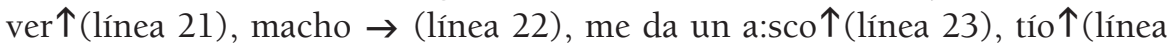
24). Su despliegue de indignación concluye con un encadenamiento de insultos (líneas 25-26).

El estilo de expresión de emociones de Diego en este fragmento ejemplifica uno de esos rasgos que contribuyen a "masculinizar" la práctica de formas de comunicación estereotípicamente femeninas en estas charlas entre operarios. Como hemos señalado en anteriores ocasiones, las quejas constituyen una de estas actividades comunicativas que se relacionan generalmente con las muje- 
res, pero ello no quiere decir que sean incompatibles con una identidad masculina convencional, contrariamente a lo sugerido por Günthner (1997), ya que su estilo de realización y la temática en la que se centren pueden hacerlas "aceptables" desde el punto de vista de las normas del habla masculina (Acuña Ferreira, 2008, 2009b). En el caso de que se refieran a cuestiones de trabajo, como el que aquí nos ocupa, no sólo pueden resultar "aceptables", sino que incluso podrían considerarse como "típicamente masculinas", teniendo en cuenta que la afiliación en contra de los superiores tiene un papel esencial en la construcción de las identidades masculinas de clase trabajadora (Connell, 1995). Por tanto, este tipo de quejas entre hombres no deberían resultar extrañas. El estudio sociológico de Hanna (1981), de hecho, destaca que los hombres de clase trabajadora suelen criticar a sus jefes en su ausencia, cuando disfrutan de sus ratos de ocio en los bares.

\subsection{Multiplicidad de usos en la producción de historias}

En esta última sección nos centraremos en mostrar los diversos usos del apelativo macho que se concentran en la producción de historias. La primera de ellas constituye una historia divertida que se ha considerado como parte del habla humorística que también desarrollan los trabajadores durante sus descansos, con el fin de alegrar el ambiente y potenciar una atmósfera de trabajo positiva. Diego está hablando a Roberto del camión que tiene el padre de un amigo suyo y de lo que ocurrió un día cuando viajaba con él en este vehículo:

\section{Fragmento 4. Historia divertida sobre el camionero}

1 Diego el viejo tiene un escania $\uparrow$

2 que puedes cagar por la pata macho $\rightarrow$

3 yo fui una vez con él $\uparrow$

$4<1.5>$

5 y fue a ver a un: $\rightarrow$

6 sobrino $\uparrow$

7 ahí a jugar a un partido de fútbol a jugar $\rightarrow$

8 ahí a \#topónimo\#?

$9<1>$

$10 \quad$ y no nos dejaban entrar $\uparrow$

11 macho $\rightarrow$

$12<1>$

13 había que $\rightarrow$

14 o sea:: $\rightarrow$ 
15
$\{$ [ac] NOS DEJABAN ENTRAR $\uparrow$ PERO HABÍA QUE PAGAR $\uparrow$

NO?\}

y dijo el padre $\rightarrow$

el padre es un animal $\uparrow$

que te cagas eh?

es un: $\rightarrow$

cacho mole $\uparrow$

destes $\rightarrow$

una barriga $\uparrow$

bebe cerveza como una bestia $\uparrow$

el cabrón $\rightarrow$

$<1>$

y coge $\uparrow<$ riéndose>

$\mathrm{y} \rightarrow$

NO LE DA?

no:: $\uparrow$

bum bum bum $\uparrow<$ imitando el ruido del motor del camión > con la cabina $\uparrow$

$<$ hace ruidos para simular el aparcamiento del camión> RAS $\uparrow$

$\{[a c]$ enfrente del campo de fúbol $\uparrow$

ó carallo $\rightarrow$

a mirar el $\} \rightarrow$

he he he

desde o camión afuera $\uparrow$

así $\rightarrow$ <probable realización de gestos>

$<1>$

$\{[\mathrm{ac}]$ puso el camión de frente $\uparrow$

a mirar el partido $\uparrow$

desde encima del muro $\rightarrow$

oíste?\}

el fulano quedou máis jodido que dio:s $\downarrow$

aparte está el portalón $\uparrow$

no?

de entrar $\uparrow$

y nosotros aquí $\rightarrow$

$<$ l>

donde empieza el muro $\uparrow$ 
55

56

57

58

59

60

61

62

63

64

65

66

67

68

69

70

71

72

73

74

75

76

77
ZAS $\rightarrow$

le dio patrás $\uparrow$

palante $\rightarrow$

$<$ simula los ruidos del camión >

lo metió ahí $\uparrow$

<simula los ruidos del camión>

pues mira $\rightarrow$

$\{[\mathrm{ac}]$ ala $\uparrow$

a mirar o partido $\downarrow \downarrow$

..

e con música a toda $\rightarrow$

alí música $\uparrow$

$<$ canturrea $>=$

Roberto = he he he $=$

Diego = he he he

el fulano quedou máis jodido que dio:s $\uparrow<$ riéndose>

ma::cho $\rightarrow$

$<1.5>$

me cago en dio:s $\uparrow$

$<1.5>$

$\{[\mathrm{p}]$ qué risa macho $\rightarrow$

es la hostia con él $\} \rightarrow$

$<2>$

Tras destacar el enorme tamaño del camión que posee el padre de su amigo (líneas 1-2), Diego anuncia la historia de un viaje que hizo con él en ese vehículo (línea 3), para ver un partido de fútbol en el que iba a participar un sobrino de este personaje (líneas 5-8). Instantes después, Diego expresa su fastidio por el problema con el que se encuentran al llegar a su destino y hace un primer uso de macho que trata de llamar la atención de su interlocutor sobre esta complicación de la historia (Labov y Waletzky, 1967; Labov, 1972) y al mismo tiempo de suscitar su empatía: y no nos dejaban entrar $\uparrow$ (línea 10), macho $\rightarrow$ (línea 11). A continuación, el narrador puntualiza que no se permitía la entrada de manera gratuita, sino que había que pagar (líneas 13-17), y de este modo anticipa el interés de los hechos como la historia de una transgresión, ya que el fastidio o la queja expresada previamente por esta circunstancia sugiere que los personajes no tenían intención de cumplir con las normas. Antes de proseguir con la reconstrucción de los hechos, Diego ofrece una descripción bastante detallista de su acompañante, el camionero: su talla es enorme, el padre es un animal (línea 19), que te cagas eh? (línea 20), es un: 
$\rightarrow$ (línea 21), cacho mole $\uparrow$ (línea 22), y tiene mucha barriga porque se atiborra de cerveza, una barriga $\uparrow$ (línea 25), bebe cerveza como una bestia $\uparrow$ (línea 26), el cabrón $\rightarrow$ (línea 27). Mediante esta descripción enfática de su enorme tamaño y de su predilección por la cerveza, el camionero es ensalzado como un héroe masculino.

En los siguientes turnos la producción de la historia entra en su fase de resolución (Labov y Waletzky, 1967; Labov, 1972). Ahora Diego explica cómo el camionero soluciona el problema antes resaltado aparcando su camión de tal forma que se podía ver el partido dentro del mismo sin necesidad de acceder al campo. El narrador anuncia este desenlace riéndose (línea 29), para resaltar su valor humorístico, y seguidamente reconstruye las maniobras que realizó el protagonista con sumo detalle (líneas 30-36); en la grabación sólo se puede apreciar que simula los ruidos del camión para representar la escena (líneas 33-36), pero es probable que también esté imitando los movimientos que va efectuando el camionero. Más exactamente, la reconstrucción de esta acción clave estaría apoyada, por tanto, en la introducción de kinefonografías (Poyatos, 1994a, 1994b).

Una vez explicado en qué consistió la estrategia del protagonista, el narrador ensalza el ingenio de su compañero de viaje destacando que el vehículo quedó situado justo enfrente del campo de fútbol (líneas 37), expresa la felicidad experimentada con esta transgresión, ó carallo $\rightarrow$ (línea 38), a mirar el $\}$ $\rightarrow$ (línea 39), he he he (línea 40), y se esfuerza por aclarar cómo quedó aparcado el camión, apoyándose de nuevo probablemente en la realización de gestos, desde o camión afuera $\uparrow$ (línea 41), así $\rightarrow$ (línea 42). En vista de que Roberto no se ríe (línea 43), Diego insiste en lo idónea que resultaba la situación del camión para ver el partido (líneas 44-46), apela directamente a su interlocutor mediante ¿oíste? (línea 47) y celebra la táctica de su amigo por la victoria que supuso sobre el hombre encargado de la venta de entradas, el fulano quedou máis jodido que dio:s $\downarrow$ (línea 48).

Buscando una valoración positiva de los hechos por parte del destinatario de la historia, Diego reconstruye la estrategia del camionero una vez más (líneas 49-60; véase que emplea otra vez recursos kinésico-paralingüísticos) y hace referencia a la posibilidad de escuchar música durante el partido para enfatizar la comicidad de la situación (líneas 62-66). Su canturreo (línea 67) logra finalmente hacer reír a Roberto (línea 68). Concluyendo la historia, Diego se refiere de nuevo burlonamente al fastidio que supuso la maniobra para el hombre de la taquilla con el objetivo de ensalzar implícitamente el ingenio de su amigo el camionero, el fulano quedou máis jodido que dio:s $\uparrow($ línea 70 ) y hace un uso suplicante de macho para reclamar el reconocimiento de su interlocutor, ma::cho $\rightarrow$ (línea 71). Tras una pausa (línea 72), el narrador expresa de nuevo 
una enorme satisfacción por el éxito de la transgresión, me cago en dio:s $\uparrow$ (línea 73) y pone fin a la narración evaluando los hechos como una aventura muy divertida, qué risa macho $\rightarrow$ (línea 76) y elogiando al protagonista, es la hostia con él $\rightarrow$ (línea 77); obsérvese que la evaluación final de los hechos como una historia extremadamente divertida está reforzada por un tercer uso del apelativo macho. Esta evaluación final trata de enfatizar el motivo por el que se ha contado la historia, buscando una vez más la valoración positiva de la misma por parte del interlocutor.

El Fragmento 5 ha sido extraído de otra interacción entre Diego y Roberto, que se centra igualmente en la producción de una historia por parte del primero. Aquí también puede apreciarse cómo el apelativo macho es empleado varias veces por este operario con distintos significados, aunque en este caso los matices van en una dirección diferente. Mientras que la historia anterior trataba sobre una pequeña aventura divertida que Diego vivió con sus amigos masculinos, la que vamos a analizar ahora gira en torno a una conversación íntima que este trabajador mantuvo recientemente con su pareja. Se trata, por tanto, de una confidencia personal que deja al descubierto la relación más profunda de amistad (y no de simple compañerismo) que mantienen estos dos trabajadores y que hemos considerado como un subtipo de habla en privado. Con ella vuelve a ponerse de relieve la práctica de actividades que se consideran propias o características de la conversación femenina entre los operarios de esta fábrica, pero también el despliegue de estrategias orientadas a "masculinizar" el discurso ${ }^{10}$ :

\section{Fragmento 5. Confidencia personal}

$\begin{array}{rll}1 & \text { Diego } & =\text { hoxe ghanei máis puntos que dios } \downarrow \\ 2 & & <2> \\ 3 & & \text { non pinei } \uparrow \\ 4 & & \text { pero me cagho en dios: } \uparrow \\ 5 & & \text { he he he } \\ 6 & & <4> \\ 7 & & \text { dios } \uparrow \\ 8 & & \text { que ben me portei } \uparrow \\ 9 & & \text { con: } \rightarrow \\ 10 & \text { Roberto } & {[\mathrm{e} \text { logho? }]} \\ 11 & \text { Diego } & [\mathrm{xx})]= \\ 12 & \text { Roberto } & =\mathrm{e} \operatorname{logho} ?=\end{array}$

10 Lo que hemos considerado como habla en privado incluye además los cotilleos acerca de compañeros de trabajo, otra variedad de discurso que, en general, se relaciona estereotípicamente con el "habla de las mujeres". 







$\begin{array}{lll}50 & \text { Diego } & \text { ho::stia macho } \rightarrow \\ 51 & & \text { qué risas } \rightarrow \\ 52 & <2>\end{array}$

En los primeros turnos, Diego anuncia un logro personal a través de la expresión coloquial, hoxe ghanei máis puntos que dios $\downarrow$ (línea 1), y seguidamente lleva a cabo un despliegue de euforia (líneas 2-9). El estilo humorístico con el que enfatiza lo feliz que se siente, non pinei $\uparrow$ (línea 3), pero me cagho en dios: $\uparrow$ (línea 4), he he he (línea 5), indica indirectamente que ese logro tiene que ver con su novia y además resulta muy estereotípicamente masculino, no sólo por el uso de exclamaciones "ordinarias" (líneas 4, 7), sino también por la alusión que se hace al hecho de que no hubo sexo en el encuentro (línea 3). Tras las preguntas de interés de Roberto (líneas 10, 12), Diego utiliza el verbo coloquial barallar para especificar que su logro se debe a que estuvo hablando extensamente con su pareja (línea 14), cuestión que se destaca implícitamente como algo "extraordinario" cuando a continuación utiliza macho para llamar la atención de su interlocutor sobre ello (línea 15). Después de reírse y de hacer una pausa (líneas 16-17), Diego señala de manera enfática lo "extraordinario" que resulta que él tenga este comportamiento y vuelve a apelar a su interlocutor mediante el uso de macho, que en esta declaración tan personal actúa como marcador de proximidad con él, BARALLÉ $\uparrow$ (línea 18), LO QUE NO BARALLÉ EN MI VIDA (línea 19), MACHO $\rightarrow$ (línea 20). En este punto es donde la charla adquiere un tono más íntimo y confidencial.

Sin embargo, en los siguientes turnos el discurso de este trabajador se va haciendo cada vez menos serio. Centrándose en la conversación que mantuvo con su pareja, Diego reproduce las palabras de la chica elogiándole por lo "bien" que él mismo le estaba hablando (líneas 21-26); en este segmento de discurso referido directo se aprecia que el hablante agudiza su tono de voz y que emplea un volumen piano para recrear una voz femenina prototípica, de forma un tanto burlona. Acto seguido, Diego parece reconstruir su propia respuesta aceptando este cumplido, É QUE EU FALO $\rightarrow$ (línea 27), MO::I BIEN $\uparrow$ (línea 28), MOI BIEN $\rightarrow$ (línea 29), e instantes después revela a su compañero que en ese momento se estaba acordando de él; esta revelación conlleva un despliegue de complicidad que está reforzado por un nuevo uso apelativo de macho, y pensando en ti macho $\rightarrow$ (línea 32). Roberto se ríe para reafirmar esta complicidad (línea 33). En las líneas siguientes se recoge una repetición parcial de los comentarios de las líneas 27-29, que parecían responder al cumplido de la chica; ahora Diego deja claro que se trataba de sus pensamientos durante su conversación con ella (líneas 34-36). La reproducción de la misma 
continúa con la pregunta que le hace su pareja sobre las razones por las que se está riendo (líneas 38-39; véase que a este personaje se le atribuye nuevamente una voz femenina prototípica). Diego reconstruye su respuesta evasiva (líneas 40-41), repite una vez más, MOI BIE::N $\uparrow$ (línea 42), (estoy) HABLANDO $\uparrow$ (línea 43), MOI BIEN $\rightarrow$ (línea 44), y hace una representación onomatopéyica de sus carcajadas (líneas 46-48). De modo semejante a lo que observamos en la historia anterior, el hablante concluye enfatizando su evaluación de los hechos como una situación divertida mediante el uso de hostia macho como fórmula de contacto y del qué exclamativo, ho::stia macho $\rightarrow$ (línea 50), qué risas $\rightarrow$ (línea 51).

En este fragmento se destaca un fuerte contraste en el modo en el que Diego habla de algo que tiene que ver con su vida personal. En los primeros turnos, la interacción se sitúa dentro de un marco de habla intima debido a que este trabajador expresa sus sentimientos positivos por una conversación que mantuvo recientemente con su pareja y confiesa que nunca había hablado tan extensamente con ella. Sin embargo, la reconstrucción de esa conversación que se lleva a cabo en los siguientes turnos resulta desconcertante, ya que en lugar de centrarse en las partes de la misma que puedan explicar por qué fue tan satisfactoria y positiva, Diego selecciona un punto en el que se ríe a carcajadas ante la forma en la que su novia elogia su discurso y responde evasivamente cuándo ésta le pregunta a qué se debe esta reacción. La repetición que hace burlonamente de las palabras de la chica constituye una recreación de sus pensamientos que actúa como un guiño al interlocutor. El enunciado que recoge la línea 32, "y pensando en ti macho", y la risa de complicidad de Roberto (línea 33), sugieren que esa especie de cantinela que se repite podría estar relacionada con un chiste interno (Norrick, 1993: 6), esto es, un chiste que sólo pueden entender los dos participantes, porque sólo ellos conocen su trasfondo humorístico.

En cualquier caso, lo que resulta evidente es que esta repetición paródica sirve a Diego para restar importancia a sus intervenciones en la conversación íntima de pareja que estaba teniendo lugar. Ante su amigo Roberto, el trabajador no valora esa conversación seriamente, sino que la afronta desde un punto de vista exclusivamente humorístico para reafirmar su masculinidad ${ }^{11}$. Así, lo que comenzó como una revelación de sentimientos acaba transformándose en la representación de una situación en la que Diego "se echó unas risas" y, por tanto, en una historia estereotípicamente "masculina". El discurso también

11 Ervin-Tripp y Lampert (1992) y Lampert (1996) también destacan el empleo masculino del humor como estrategia para trivializar el discurso cuando está adquiriendo un tono demasiado íntimo. 
está masculinizado por la intercalación de humor sexual y por la recreación burlona que se hace de la voz femenina (McConnell-Ginet, 1978: 549-50).

Los usos del apelativo macho que el hablante realiza en varios puntos de su discurso adquieren fundamentalmente dos significados, que están ligados a cada una de esas dos orientaciones tan distintas que presenta el habla recogida en el fragmento. Los dos primeros (líneas 15, 20) contribuyen a reforzar el marco de habla íntima y personal que se establece cuando Diego confiesa que nunca había hablado tanto con su pareja, mientras que los que se producen después, cuando este trabajador se centra en resaltar el hecho de que las palabras de su novia le hicieron recordar una gracia o un chiste que comparte con su interlocutor (líneas 32, 50) tratan de suscitar su complicidad masculina en este tratamiento trivializado, poco serio de la comunicación con la pareja. La risa de Roberto en la línea 33 indica que la estrategia tiene éxito.

\section{Conclusiones}

En este artículo hemos destacado la tradicional falta de atención específica al habla de los hombres en los estudios sobre género y discurso, como consecuencia del intenso debate que se ha mantenido en torno a los rasgos positivos o negativos del "habla de las mujeres", y también el escaso desarrollo que ha tenido esta línea de investigación dentro del ámbito particular de la sociolingüística hispánica, tanto en lo que respecta al habla femenina como a la masculina.

Con el objetivo de contribuir a un mejor conocimiento del "habla de los hombres" dentro del contexto hispánico y del campo de los estudios sobre género y discurso en general, en el presente artículo hemos analizado una selección de fragmentos extraídos de conversaciones mantenidas por los operarios gallegos de una fábrica durante los descansos que hacen en su jornada de trabajo. Nuestro análisis se ha centrado en el uso frecuente que se hace del apelativo macho, con el fin de resaltar su importancia en la expresión de solidaridad masculina y de establecer algunas de las múltiples funciones que esta partícula pragmática puede desempeñar de manera más específica.

En nuestros datos, las funciones específicas del apelativo macho aparecen íntimamente ligadas a los subtipos particulares de discurso que se desarrollan en el corpus. Así, en las charlas de cortesía que se orientan más puramente hacia la expresión de cordialidad y de compañerismo, el empleo recíproco de este apelativo entre dos trabajadores contribuye a acentuar esta finalidad de la interacción. En el habla peyorativa sobre los gays, que también tiene como meta el mantenimiento de buenas relaciones entre los trabajadores, pero apoyándose en el despliegue de homofobia, el uso recíproco del apelativo macho se orienta más concretamente hacia la expresión de complicidad masculina en 
contra de este colectivo, mientras que en la producción de quejas acerca de los superiores, su uso puede considerarse como parte de las estrategias que se despliegan para suscitar la empatía y el apoyo del interlocutor. Por último, en los fragmentos de producción de historias se ha observado cómo el narrador apela varias veces a su interlocutor mediante el uso de macho con diversos propósitos, según la orientación de su discurso en cada punto de la narración. Así, ante la introducción de un suceso negativo que le ha perjudicado dentro del mundo de la historia, el empleo de este apelativo se resalta como una forma de suscitar la empatía del interlocutor; ante la exaltación de acciones que se consideran divertidas se utiliza como un recurso para reclamar su acuerdo con esta valoración, mientras que en la introducción de acontecimientos que tienen que ver con la vida personal del hablante contribuye a acentuar el tono íntimo y de confianza hacia el que se quiere dirigir la conversación. En el tratamiento humorístico e incluso burlón de la comunicación con la pareja femenina, el empleo de macho sirve para suscitar la complicidad masculina del interlocutor, de modo semejante a lo que también sucedía en el habla peyorativa sobre los gays.

En general, todos estos usos del apelativo macho cumplen la función de realzar la construcción de solidaridad masculina como una de las metas fundamentales que tienen todos y cada uno de los tipos y subtipos de charla de descanso en los que se implican los operarios, de acuerdo con lo señalado por Beinhauer (1978 [1929]: 48-9; véase también López García y Morant, 1991: 99). A través del análisis de los usos más específicos de este apelativo, en este artículo hemos querido mostrar la diversidad de formas en que el habla de los hombres puede orientarse firmemente hacia esta construcción de solidaridad e incluso a la búsqueda del apoyo o la empatía del interlocutor, teniendo en cuenta que sus modelos comunicativos han sido relacionados a menudo exclusivamente, y de manera más o menos explícita, con la competición y la reafirmación del estatus personal ante los demás. De este modo hemos querido contribuir también a debilitar las concepciones estereotipadas y excesivamente contrapuestas de los estilos conversacionales que se atribuyen a cada sexo.

No obstante, con ello no pretendemos negar la importancia que pueden adquirir las diferencias y estereotipos de género en el discurso, ya que en nuestro análisis también se ha destacado el papel de la homofobia y del tratamiento trivializado de las mujeres. Por esta razón, consideramos que las investigaciones futuras en este campo deberían prestar más atención a las bases sobre las que se asienta la realización de solidaridad en el habla entre hombres, en lugar de atribuirle como única meta la competición por el status, en contraposición implícita o explícita con el habla de las mujeres. 


\section{Referencias bibliográficas}

Acuña Ferreira, A.V. (2002): Géneros comunicativos en contextos femeninos y masculinos: las historias de queja. Tesis de Licenciatura no publicada, Universidade de Vigo.

Acuña Ferreira, A.V. (2002/2003): "Gendered emotive displays in complaint discourse", Estudios de Sociolingüística, 3(2) y 4(1), págs. 139-172.

Acuña Ferreira, A.V. (2004): "Complaint stories in male contexts: The power of emotions", Spanish in Context, 1, págs. 181-213.

Acuña Ferreira, A.V. (2008): "Complaint stories revisited: The "masculine" performance of a "feminine" narrative genre in a conversation among Galician men", Sociolinguistic Studies, 2, págs. 185-220.

Acuña Ferreira, A.V. (2009a): "Review of Janet Holmes. Gendered talk at work. Constructing gender identity through workplace discourse", Sociolinguistic Studies, 3, págs. 115-121.

Acuña Ferreira, A.V. (2009b): Género y discurso. Las mujeres y los hombres en la interacción conversacional. Múnich, Lincom.

Acuña Ferreira, V. y S. Álvarez López (eds.) (2003): Lingua e xénero: un enfoque interdisciplinario. Vigo, Servizo de Publicacións da Universidade de Vigo.

Álvarez Cáccamo, C. (1990): The Institutionalization of Galician: Linguistic Practices, Power, and Ideology in Public Discourse. Tesis Doctoral no publicada, University of California at Berkeley.

Álvarez-López, S. (2002/2003): "Functions and strategies of male humour in crossgender interactions", Estudios de Sociolingüística, 3(2) y 4(1), págs. 173-205.

Aries, E.J. (1996): Men and women in interaction. Reconsidering the differences. Oxford, Oxford University Press.

Baron, B. y H. Kothoff (2002): Gender in interaction. Perspectives on feminity and masculinity in ethnography and discourse. Amsterdam, John Benjamins.

Beinhauer, W. (1978 [1929]): El español coloquial. Madrid, Gredos.

Bengoechea, M. (1995): "Mujeres/hombres: el conflicto entre dos culturas", Revista de Occidente, 170 y 171, págs. 120-136.

Bergvall, V., J. Bing y A. Freed (eds.) (1996): Rethinking language and gender research: Theory and practice. Londres, Longman.

Bing, J. y V. Bergvall (1996): "The question of questions: Beyond binary thinking". En Bergvall, V., J. Bing y A. Freed (eds.), Rethinking language and gender research: Theory and practice. Londres, Longman, págs. 1-30.

Boxer, D. (1993): "Social distance and speech behavior: The case of indirect complaints", Journal of Pragmatics, 19, págs. 103-125.

Bucholtz, M., A.C. Liang y L. Sutton (1999): Reinventing identities. The gendered self in discourse. Nueva York, Oxford University Press.

Calero Fernández, M.A. (1999): Sexismo lingüístico. Análisis y propuestas ante la discriminación sexual en el lenguaje. Madrid, Narcea.

Cameron, D. (1997): "Performing gender identity: Young men's talk and the construction of heterosexual masculinity". En Johnson, S. y U.H. Meinhof (eds.), Language and masculinity. Oxford, Blackwell, págs. 47-64. 
Coates, J. (1988): "Gossip revisited: Language in all-female groups". En Coates, J. y D. Cameron (eds.), Women in their speech communities. New perspectives on language and sex. Londres, Longman, págs. 94-122.

Coates, J. (ed.) (1998): Language and gender: A reader. Oxford, Blackwell.

Coates, J. (1996): Women talk. Conversation between women friends. Oxford, Blackwell.

Coates, J. (1997a): "The construction of a collaborative floor in women's friendly talk". En Givón, T. (ed.), Conversation. Cognitive, communicative and social perspectives. Amsterdam, John Benjamins, págs. 55-89.

Coates, J. (1997b): "Women's friendships, women's talk". En R. Wodak (ed.), Gender and discourse. Londres, Sage, págs. 245-262.

Coates, J. (1997c): "One-at-a-time: the organization of men's talk". En S. Johnson y U.H. Meinhoff (eds.), Language and masculinity. Oxford, Blackwell, págs. 107-129.

Coates, J. (2003): Men talk. Stories in the making of masculinities. Oxford, Blackwell.

Connell, R.W. (1995): Masculinities. Cambridge, Polity Press.

Coupland, J. (ed.) (2000): Small talk. Londres, Longman.

Crawford, M. (1995): Talking difference. On gender and language. Londres, Sage.

Edelsky, C. (1981): "Who's got the floor?", Language in Society, 10, págs. 383-421.

Edley, N. y M. Wetherell (1997): "Jockeying for position: The construction of masculine identities", Discourse \& Society, 8, págs. 203-217.

Eggins, S. y D. Slade (1997): Analysing casual conversation. Londres, Continuum.

Ervin-Tripp, S. y M.D. Lampert (1992): "Gender differences in the construction of humorous talk”. En K. Hall, M. Bucholtz y B. Moonwomon (eds.), Locating power. Proceedings of the Second Berkeley Women and Language Conference. Volume 1. Berkeley, CA, University of California, págs. 108-117.

García Meseguer, A. (1994): ¿Es sexista la lengua española? Una investigación sobre el género gramatical. Barcelona, Paidós.

García Mouton, P. (1999): Cómo hablan las mujeres. Madrid, Arco-Libros.

García Mouton, P. (2003): Así hablan las mujeres: curiosidades y tópicos del uso femenino del lenguaje. Madrid, La Esfera de los Libros.

Gough, B. y G. Edwards (1998): "The beer talking: Four lads, a carry out and the reproduction of masculinities", The American Sociological Review, págs. 409-435.

Günthner, S. (1997): "Complaint stories. Constructing emotional reciprocity among women”. En Kotthoff, H. y R. Wodak (eds.), Communicatin gender in context. Amsterdam, John Benjamins, págs. 179-218.

Hall, K. y M. Bucholtz (eds.) (1995): Gender articulated. Language and the socially constructed self. Londres, Routledge.

Hanna, Ch.F. (1981): "Complaint as a form of association", Qualitative Sociology, 4, págs. 298-311.

Holmes, J. (2000): "Doing collegiality and keeping control at work: Small talk in government departments”. En Coupland, J. (ed.), Small talk. Londres, Longman, págs. 32-61. 
Holmes, J. (2006): Gendered talk. Constructing gender identity through workplace discourse. Oxford, Blackwell.

Holmes, J. y M. Meyerhoff (eds.) (2003): The handbook of language and gender. Oxford, Blackwell.

Holmes, J. y M. Stubbe (2003): Power and politeness in the workplace. A sociolinguistic analysis of talk at work. Londres, Longman.

Johnson, S. (1997): "Theorizing language and masculinity: a feminist perspective". En S. Johnson y U.H. Meinhof (eds.), Language and masculinity. Oxford, Blackwell, págs. 8-26.

Johnson, S. \& F. Finlay (1997): "Do men gossip? An analysis of football talk on television". En Johnson, S. y U.H. Meinhof (eds.), Language and masculinity. Oxford, Blackwell, págs. 130-143.

Johnson, S. y U.H. Meinhof (eds.) (1997): Language and masculinity. Oxford, Blackwell.

Jones, D. (1980): "Gossip: Notes on women's oral culture", Women's Studies International Quarterly, 3, págs. 193-198.

Labov, W. y J. Waletzky (1967): "Narrative analysis". En J. Helm (ed.), Essays on the verbal and visual arts. Seattle, University of Washington Press, págs. 12-44.

Labov, W. (1972): Language in the inner city. Filadelfia, University of Pennsylvania Press.

Lakoff, R. (2004 [1975])). Language and woman's place. Text and commentaries. Oxford, Oxford University Press.

Lampert, M.D. (1996): "Studying gender differences in the conversational humor of adults and children”. En Slobin, D.I., J. Gerhardt, A. Kyratzis y J. Guo (eds.), Social interaction, social context, and language. Essays in honor of Susan Ervin-Tripp. Mahwah, NJ, Lawrence Erlbaum Associates, págs. 579-596.

LeMasters, E.E. (1975): Blue collar aristocrats: Life-styles at a working-class tavern. Madison, University of Wisconsin Press.

Livia, A. y K. Hall (eds.) (1997): Queerly phrased: Language, gender and sexuality. Nueva York, Oxford University Press.

Leet-Pellegrini, H. M. (1980): "Conversational dominance as a function of gender and expertise". En Giles, H., W.P. Robinson y P.M. Smith (eds.), Language: social psychological perspectives. Oxford, Pergamon, págs. 97-104.

López García, A. y R. Morant (1991). Gramática femenina. Madrid, Cátedra.

Lozano-Domingo, I. (1995): Lenguaje femenino, lenguaje masculino. Madrid, Minerva. Malinowski, B. (1949 [1923]): "The problem of meaning in primitive languages". En C.K. Ogden y I. Richards (eds.), The meaning of meaning. Londres, Routledge y Kegan Paul, págs. 269-336.

Martín Rojo, L. (1996): "Lenguaje y género. Descripción y explicación de la diferencia", Signos, Octubre-Diciembre, págs. 6-17.

McConnell-Ginet, S. (1978): "Intonation in a man's world", Signs, 3, págs. 541-559.

McConnell-Ginet, S. (2004): "Positioning ideas and gendered subjects: "Women's language" revisited". En R. Lakoff, Language and woman's place. Text and commentaries. Oxford, Oxford University Press, págs. 136-142. 
Mills, S. (2003): Gender and politeness. Cambridge, Cambridge University Press.

Pichler, P. y E. Eppler (eds.) (2009): Gender and spoken interaction. Londres, Palgrave McMillan.

Placencia, M.E. y C. García (2008): "Formas, usos y funciones del habla de contacto en español. Introducción", Oralia, 11, págs. 9-28.

Poyatos, F. (1994a): La comunicación no verbal, I. Cultura, lenguaje y conversación. Madrid, Istmo.

Poyatos, F. (1994b): La comunicación no verbal, II. Paralenguaje, kinésica e interacción. Madrid, Istmo.

Pujolar, J. (1997a): ¿De qué vas, tío? Barcelona, Empúries.

Pujolar, J. (1997b): Masculinities in a multilingual setting. En S. Johnson y U.H. Meinhof (eds.), Language and masculinity. Oxford, Blackwell, págs. 86-106.

Pujolar, J. (2002): Gender, power and heteroglossia: A sociolinguistic study of youth culture. Berlín, Mouton de Gruyter.

Romaine, S. (1999): Communicating gender. Mahwah, New Jersey, Lawrence Erlbaum Associates.

Sacks, H., E.A. Schegloff y G. Jefferson (1974). "A simplest systematics for the organization of turn-taking for conversation”, Language, 50, págs. 696-735.

Sacks, H. (1995): Lectures on conversation (vols 1 and 2). Edited by Gail Jefferson. Oxford, Blackwell.

Santaemilia, J., B. Gallardo y J. Sanmartín (eds.) (2002): Sexe i llenguatge: la construcció lingüística de les identitats de gènere. Valencia, Universitat de València.

Sunderland, J. (2006): Language and gender. An advanced resource book. Londres, Routledge.

Talbot, M.M. (1998): Language and gender. An introduction. Oxford, Polity Press.

Tannen, D. (ed.) (1993): Gender and conversational interaction. Oxford, Oxford University Press.

Vigara Tauste, A.M․ y R.Ma Jiménez Catalá (eds.) (2002): “Genero”, sexo, discurso. Madrid, Laberinto.

West, C., M. Lazar y Ch. Kramarae (2000 [1997]): "El género en el discurso". En T.A. van Dijk (ed.), El discurso como interacción social. Barcelona, Gedisa, págs. 179-212.

Wodak, R. (ed.) (1997): Gender and discourse. Londres, Sage. 


\section{Apéndice: convenciones de transcripción}

Letra redonda

Letra negrita

Línea de transcripción

$\uparrow$

$\downarrow$

$\rightarrow$

$?$

..

$<3>$

o sea::

la lo-

allí es mucho eh?=

$=$ ya ves

y tú te estabas [meando]

[es que está] tres horas

(parece)

(xx)

.

he he he

LETRAS MAYÚSCULAS

\{\}

$\{[\mathrm{p}]\}$

$\{[\mathrm{ac}]\}$

$\{[\mathrm{a}]\}$

$<$ riéndose >

\#topónimo\#
Castellano

\section{Gallego}

Unidad de entonación

Entonación final ascendente

Entonación final descendente

Entonación final más o menos sostenida

Entonación típicamente interrogativa

Micropausa (menos de un segundo)

Pausa medida en número de segundos

Sonido alargado

Sonido truncado

Encadenamiento de voces

Superposición de voces

Transcripción dudosa

Segmento ininteligible

Omisión de varios turnos

Risa

Volumen relativamente fortis

Segmento al que afecta el fenómeno

Volumen relativamente piano

Tempo relativamente acelerado

Tono más agudo

Comentarios adicionales

Datos confidenciales 